\title{
INTERDEPENDENT DYNAMIC NITROALDOL AND BORONIC ESTER REACTIONS FOR COMPLEX DYNAMERS OF DIFFERENT TOPOLOGIES
}

\author{
Antanas Karalius, ${ }^{1}$ Yunchuan Qi, ${ }^{2}$ Mubarak Ayinla, ${ }^{2}$ Zoltán Szabó, ${ }^{1}$ and Olof Ramström*1,2,3 \\ ${ }^{1}$ Department of Chemistry, KTH - Royal Institute of Technology, Teknikringen 36, S-10044 Stockholm, Sweden; ${ }^{2}$ Department \\ of Chemistry, University of Massachusetts Lowell, One University Ave., Lowell, MA 01854, USA; Email: \\ olof_ramstrom@uml.edu; ${ }^{3}$ Department of Chemistry and Biomedical Sciences, Linnaeus University, SE-39182 Kalmar, \\ Sweden
}

\section{Abstract}

Complex dynamic systems displaying interdependency between nitroaldol and boronic ester reactions have been demonstrated. Nitroalkane-1,3-diols, generated by the nitroaldol reaction, were susceptible to ester formation with different boronic acids in aprotic solvents, whereas hydrolysis of the esters occurred in the presence of water. The boronic ester formation led to significant stabilization of the nitroaldol adducts under basic conditions. The use of bifunctional building blocks was furthermore established, allowing for main chain nitroaldolboronate dynamers as well as complex network dynamers with distinct topologies. The shape and rigidity of the resulting dynamers showed an apparent dependency on the configuration of the boronic acids.

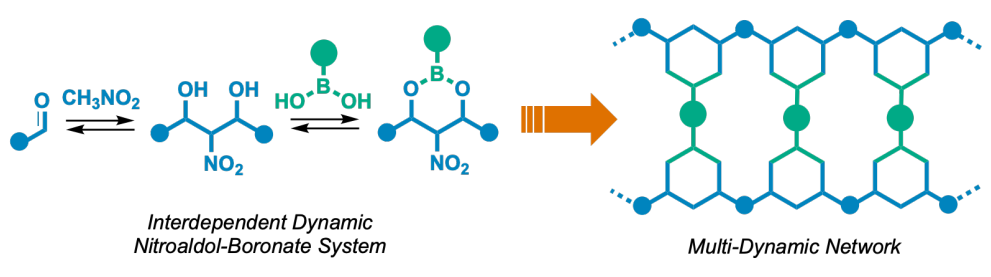

\section{Introduction}

Dynamic covalent reactions enable a wide range of molecular systems and materials.$^{[1-18]}$ For example, the reversible nature of these bond types, akin to non-covalent supramolecular interactions, leads to different self-assembly-, self-healing-, and self-replication-processes, as well as stimuli-responsive materials for a variety of applications. ${ }^{[16,19-31]}$ Systems based on dynamic covalent bonds can furthermore be applied to chemical oscillation, and lead to complex behavior, switching modes, or out-of-equilibrium regimes. ${ }^{[32-40]}$ Moreover, the unique chemistries of reversible chemical bonds enable transfer, inhibition, or emergence of systemic properties, typically based on multiple dynamic processes operating in conjunction. ${ }^{[41-44]}$ In this regard, dynamic covalent polymers (dynamers) are gaining a lot of attention due to their many features, such as self-assembly/self-organization, adaptive/responsive functions, and emergent properties. ${ }^{[1,15,45-49]}$ This is perhaps especially the case in biomedical applications and materials with functions inspired by biological systems. For example, dynamers mimicking natural biopolymers can be applied to replicate the complexity of natural systems through the exploitation of bonds that are dynamic under ambient conditions. [50,51]

A prevailing challenge with reversible covalent systems is the establishment of multiple, yet individually controllable, dynamics. Such dynamic reactions, operating either independently or in synchrony, rapidly enhance the complexities of the systems and can lead 
to increased control and unique emergent properties..$^{[9,14,52-54]}$ At the macromolecular level, examples of such systems are rare, however enabling the generation of intricate structures of different topology. ${ }^{[39,55,56]}$ By controlling the connectivities of building blocks in multiple dimensions, the constitution and overall topology of the resulting entities can be varied with high precision through self-assembly of the components.

This challenge has been addressed in the present study where such complex dynamic systems have been established and applied to dynamer formation. In complement to the dynamic nitroaldol (Henry) reaction, for example applied to dynamer formation, ${ }^{[33]}$ reversible boronic ester formation was chosen for the systems. The high chemoselectivity of boronic acids towards diols makes them attractive for a variety of structures, such as macrocycles and cages. ${ }^{[12,23,57-62]}$

In this work, we demonstrate a match between boronates and the nitroalkanol functionalities generated through the nitroaldol reaction. The two processes could operate simultaneously under the same conditions, where the boronic ester formation and the nitroaldol reaction complemented each other. This led to a double dynamic process in which the second dynamic reaction is sequentially dependent on the first, while, at the same time, the properties of the first process are altered by the second. The dynamic boronic ester process could thus change the properties of the underlying nitroaldol reaction, e.g., through increased resistance to base and impedance of the reverse nitroaldol reaction. These features could subsequently be extended to the formation and modification of nitroaldol-based dynamers, allowing the incorporation of the two dynamic bond types into topologically distinct dynamers.

\section{Results and Discussion}

The boronate formation was initially studied using phenylboronic acid a and nitroalkanediol 1, the reversible addition product between nitromethane (N1) and pyridine2-carboxaldehyde (A1; Figure 1). The reactions were followed by ${ }^{1} \mathrm{H}$ NMR in several solvents, displaying that the resulting boronic ester 1a was favored in all tested aprotic solvents, whereas methanol and water disfavored the formation. The ${ }^{11} \mathrm{~B}$ NMR spectrum of the reaction between compounds 1 and $\mathbf{a}$ in $\mathrm{CD}_{3} \mathrm{CN}$ indicated the formation of dioxaborinane 1a together with a smaller amount of a potential oxazaborolidine by-product (Figure S28). ${ }^{63]}$ Even low degrees of water in mixed solvents resulted in low stabilization of the product and the equilibrium in $\mathrm{D}_{2} \mathrm{O} / \mathrm{CD}_{3} \mathrm{CN} 10 / 90$ changed to the side of the starting materials (cf. Supporting Information). Acetonitrile was eventually chosen as the most universal solvent, exhibiting high solubilities of the starting materials and the products, while resulting in good stability of the systems over prolonged time periods.

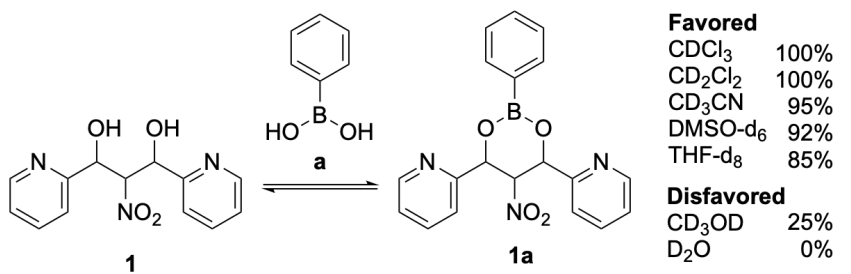

Figure 1: Formation of boronic ester 1a from nitroalkanediol 1 and phenylboronic acid $\boldsymbol{a}$ in different solvents (cf. Supporting Information for corresponding NMR spectra).

Since water-rich media proved to be unfavorable for the reversible boronate process, conditions under which both reactions could be controlled were next explored. Drawing from previous experiences using mild base in organic solvents, ${ }^{[64-66]}$ the addition of $\mathrm{NEt}_{3}(80 \mathrm{mM}$, 
2 equiv.) to acetonitrile solutions was thus evaluated for the nitroaldol dynamics, and the compatibility of these conditions with the boronate reaction was assessed. As can be seen in Figure 2, these conditions were suitable for the double dynamic system, however leading to low boronate reaction rates. Equilibration could thus be initiated by the addition of base to a solution of nitroalkanediol $\mathbf{1}$, favoring fragmentation of the diol into the mono-alcohol while releasing one equivalent of aldehyde (Figure 2A). In contrast, when the boronic ester of the nitroalkanediol (1a), preformed in situ, was applied, only a low degree of retro-nitroaldol products was observed (Figure 2B) within $12 \mathrm{~h}$. Similarly, the addition of phenylboronic acid a to a pre-equilibrated mixture of compound $\mathbf{1}$ and $\mathrm{NEt}_{3}$ resulted in low equilibration rates (Figure 2 $\mathrm{C}$ ).
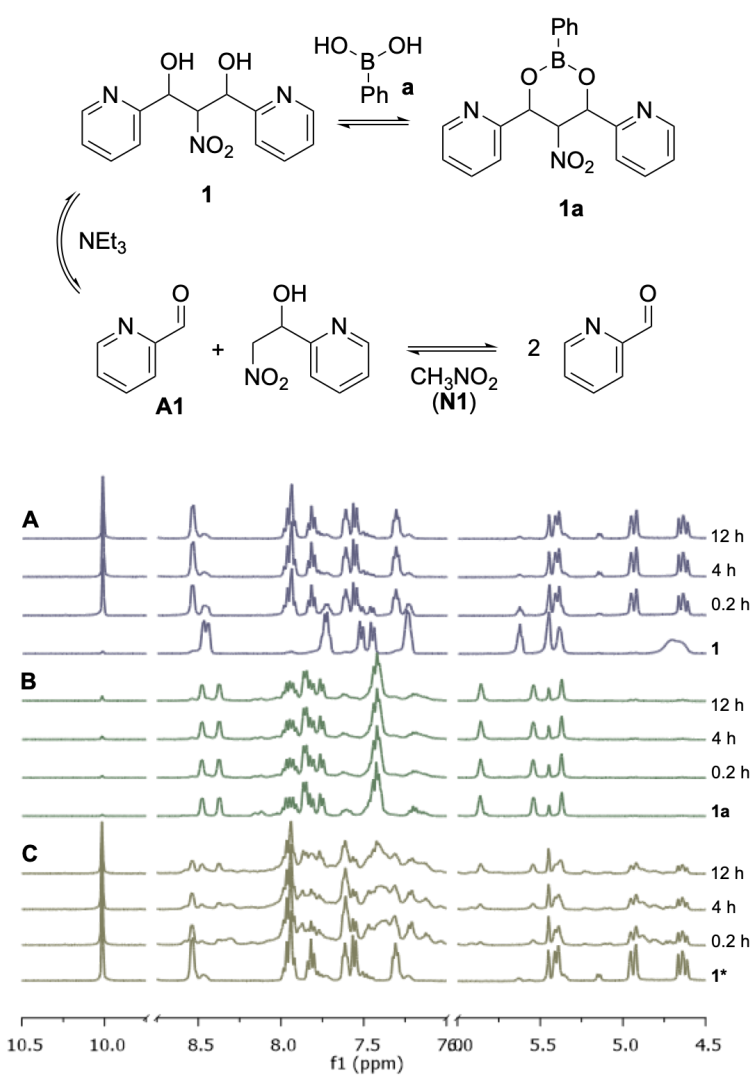

Figure 2: Multidynamic system arising from two-step nitroaldol reaction and formation of boronic ester (top). ${ }^{1} H$ NMR spectra recorded at different times during base stability tests in acetonitrile (bottom): A) initial solution of nitroalkanediol 1 and product mixture at different times after base addition; B) initial solution of boronic ester $1 \boldsymbol{a}$ and product mixture at different times after base addition; $C)$ initial mixture of nitroalkanediol 1 after $12 \mathrm{~h}$ incubation with base $\left(\mathbf{1}^{*}\right)$ and at different times after introduction of boronic acid $\boldsymbol{a}$.

A range of boronic acids was subsequently tested in order to evaluate the potential influence of different functional groups on the boronic ester formation. As can be seen in Figure $\underline{\mathbf{3}}$, complete or near-complete conversions were obtained in all cases, regardless of boronic acid structure.

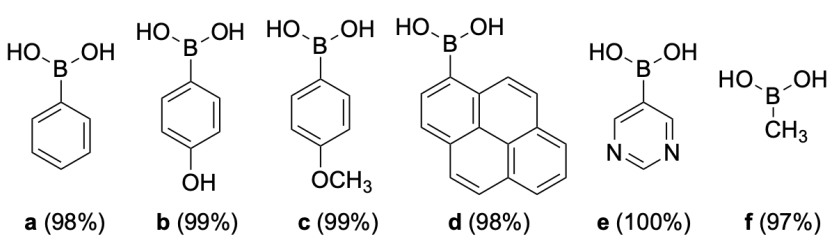

Figure 3: Boronic acids a-f and conversions to boronic esters 1 a-1f with nitroalkanediol 1 in $C D_{3} C N$. 
Having evaluated the formation of the boronate nitroalkanediol esters, the impact of the boronate reaction on the reactivity and topology of nitroaldol dynamers was addressed. In principle, several different dynamer topologies can be be envisaged in this case, involving the reversible formation and interplay of both the nitroaldol and the boronate species (Figure 4 ).

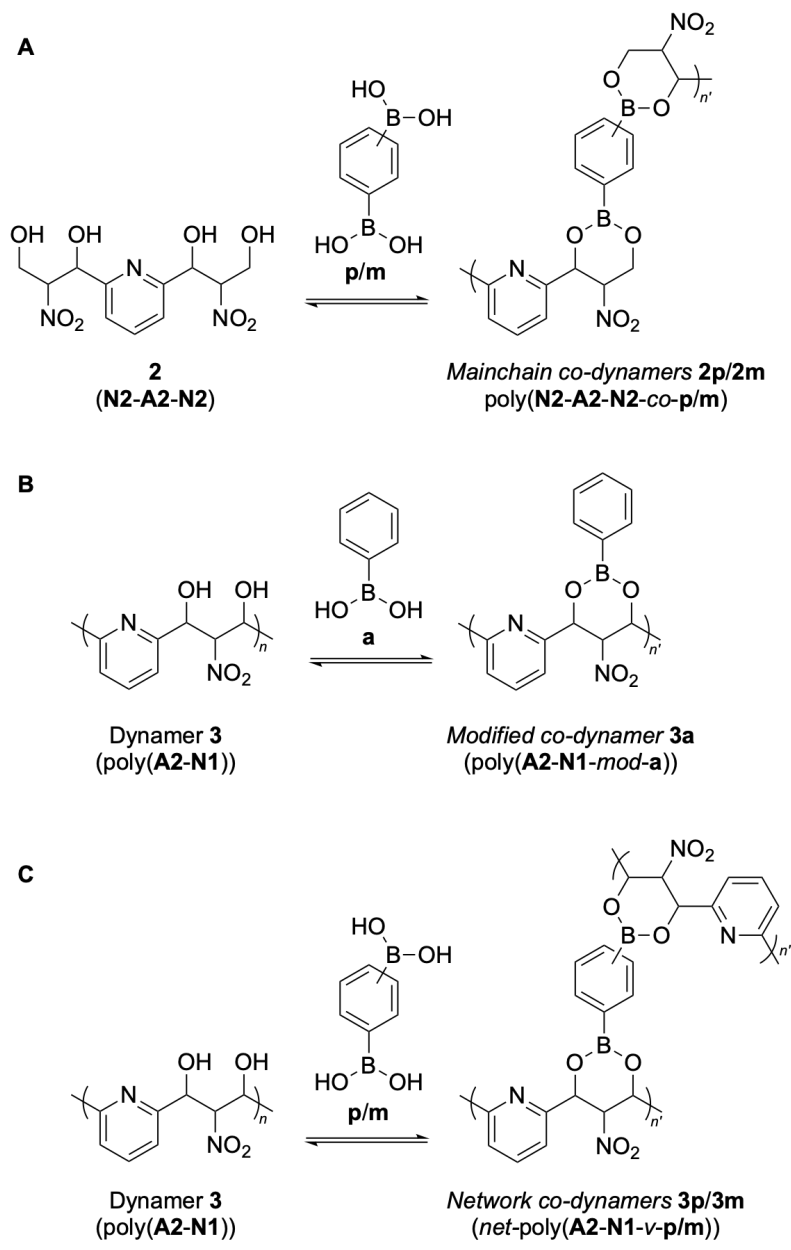

Figure 4: Formation of nitroaldol-boronate co-dynamers of different topology: A) mainchain co-dynamer from ditopic nitroalkanediol $\mathbf{2}$ and ditopic boronic acids $\boldsymbol{p}$ or $\boldsymbol{m} ; \mathrm{B}$ ) modified (graft-on) co-dynamer $3 \boldsymbol{a}$ from polytopic dynamer 3 and monotopic boronic acid $\boldsymbol{a} ; C)$ network nitroaldol-boronate co-dynamers $3 \boldsymbol{p}$ or $3 \boldsymbol{m}$ from polytopic dynamer $\mathbf{3}$ and ditopic boronic acids $\boldsymbol{p}$ or $\boldsymbol{m}$. A2 = pyridine-2,6-dicarboxaldehyde, $\mathbf{N} \mathbf{2}=2$-nitroethanol, $\boldsymbol{p}=1,4$ phenylenediboronic acid; $\boldsymbol{m}=1,3-$ phenylenediboronic acid.

A range of building blocks of each type was evaluated for the co-dynamer formation studies. Thus, compounds with one, two, or multiple reacting groups were selected, including ditopic species with different geometries. For the nitroaldol products, ditopic bisnitroalkanediol 2, produced from pyridine-2,6-dicarboxaldehyde (A2) and 2-nitroethanol (N2), and polytopic dynamer $\mathbf{3}$ (poly(A2-N1)), ${ }^{[33]}$ produced from aldehyde $\mathbf{A 2}$ and nitromethane (N1), were chosen. These nitroaldol species contain two or multiple 1,3-diol functionalities in a linear arrangement, thereby leading to main chain dynamers. Monotopic boronic acid a, and ditopic species p (1,4-phenylenediboronic acid) and $\mathbf{m}$ (1,3phenylenediboronic acid) were furthermore included, where the ditopic entities displayed linear and bent configuration, respectively. These structures were combined in stoichiometric amounts, enabling the formation of hybrid nitroaldol-boronate co-dynamers of different topology and molecular weight (Figure 4 ). 


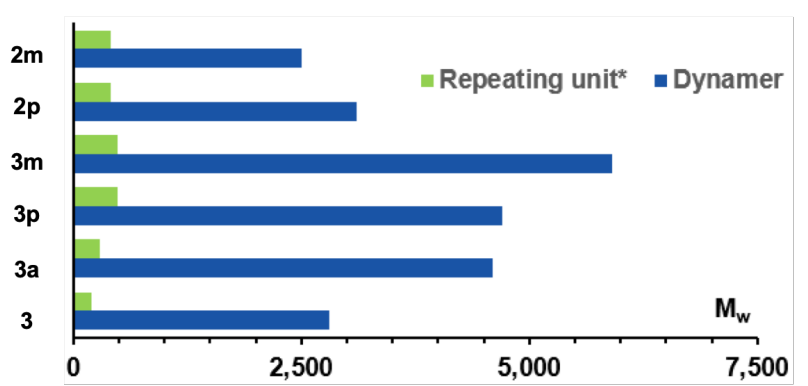

Figure 5: Relative molecular weights of combinations of nitroalkanediols and boronic acids obtained using DOSY NMR (cf. Supporting Information).

The combinations were evaluated by ${ }^{1} \mathrm{H}$ DOSY NMR and the molecular weights were estimated through comparison with reference compounds of similar composition and known molecular weights (Figure 5). The estimated average molecular weights of the main chain alternating nitroaldol-boronate co-dynamers $\mathbf{2 p}$ (poly(N2-A2-N2-co-p)), and $\mathbf{2 m}$ (poly((N2A2-N2-co-m)), formed from bivalent building blocks of both classes, were of comparable magnitude around $2800 \mathrm{~g} / \mathrm{mol}$, similar to the main chain nitroaldol dynamer $\mathbf{3}$ (poly(A2-N1)). Although the geometry of the chains would be influenced by the arrangement of the functional groups on the boronate benzene ring, this effect did not substantially affect the degree of polymerization. However, co-dynamer $\mathbf{2 m}$ resulted in a slightly smaller estimated size $(2500 \mathrm{~g} / \mathrm{mol})$ compared to the more extended co-dynamer $2 \mathbf{p}(3100 \mathrm{~g} / \mathrm{mol})$.

More pronounced differences were observed in the reactions with nitroaldol dynamer 3. When dynamer 3 was allowed to react with phenylboronic acid a, the molecular weight of codynamer 3a (poly(A2-N1-mod-a)) increased from $2800 \mathrm{~g} / \mathrm{mol}$ to $4600 \mathrm{~g} / \mathrm{mol}$, albeit without any significant change in the degree of polymerization $(\sim 15)$. This amounts to a modified (graft-)type topology of the co-dynamer, where the boronic acid units are grafted onto the main chain dynamer and cage the basic nitroaldol entities. Similarly, the reactions between nitroaldol dynamer $\mathbf{3}$ and diboronic acid building blocks $\mathbf{m}$ and $\mathbf{p}$ led to substantial increases in molecular weight, in these cases associated with noticeable aggregation as expected from the crosslinking nature of the reactions. The NMR signals broadened significantly and the analysis of the average molecular weight of the aggregates resulted in larger errors. Nevertheless, the diffusion coefficient of co-dynamer $\mathbf{3 m}$ (net-poly(A2-N1-v-m), $\mathbf{M}_{\mathrm{W}}$ $5900 \mathrm{~g} / \mathrm{mol}$ ) decreased more than the coefficient of co-dynamer 3p (net-poly(A2-N1- $v-\mathbf{p}), \mathrm{M}_{\mathrm{W}}$ $4700 \mathrm{~g} / \mathrm{mol}$ ). Since the reactivities of the diboronic acids are comparable, as seen from the results with bis-nitroalkanediol 2, this is most likely an effect of the different crosslinking modes of the two diboronic acids. The more bent geometry of diboronic acid $\mathbf{m}$ in comparison to that of boronic acid $\mathbf{p}$ could thus result in a higher degree of crosslinking (interchain crosslinking or folding), or from lower mono-saturation of the reactive nitroaldol dynamer sites (graft-type topology).

The reactions of dynamer $\mathbf{3}$ with phenylboronic acids $\mathbf{a}, \mathbf{p}$, and $\mathbf{m}$ were also evaluated by ${ }^{11} \mathrm{~B}$ NMR and FTIR spectroscopy. Although phenylboronic acid derivative 3a and boronic acid a displayed largely coincidental chemical shifts in the ${ }^{11} \mathrm{~B}$ NMR spectra, significant changes were revealed in the FTIR spectra (Figure S34). The major asymmetric B-O stretch thus shifted from $1333 \mathrm{~cm}^{-1}$ in compound a to $1304 \mathrm{~cm}^{-1}$ in modified polymer $\mathbf{3 a}$, consistent with boronic ester formation. ${ }^{[67,68]}$ On the other hand, the ${ }^{11} \mathrm{~B}$ NMR results of the diboronic acid-based combinations were more clear. The spectrum of network polymer $\mathbf{3 p}$ showed a new peak at $12.5 \mathrm{ppm}$, corresponding to boronate formation, along with a remaining boronic acid signal at $27.9 \mathrm{ppm}$ (Figures S30-S31). In addition, the FTIR spectrum displayed a shift of 
the asymmetric B-O stretch from $1335 \mathrm{~cm}^{-1}$ in compound $\mathbf{p}$ to $1296 \mathrm{~cm}^{-1}$ in structure $\mathbf{3 p}$ (Figure S35). The ${ }^{11} \mathrm{~B}$ NMR and FTIR spectra of combination $\mathbf{3 m}$ followed a pattern similar to that of structure 3p (Figures S32-S33, S36). These results underscore the dynamic formation of the boronic esters between the dynamer and the three boronic acids.

\section{Conclusions}

In summary, dynamic systems based on the combination of the nitroaldol reaction and boronic ester formation have been demonstrated. The esters were thus formed from the nitroalkanediols generated by the nitroaldol reaction in the presence of different boronic acids. The reversible boronic ester formation proved to be favored in most aprotic solvents, whereas hydrolysis was dominant in water-rich media. Both reactions were mutually dependent on each other; nitroalkanediol formation being a prerequisite for boronic ester establishment, and the esters significantly stabilizing the nitroaldol adducts under basic conditions. The systems were furthermore extended to topologically distinct nitroaldol-boronate-dynamers. In these cases, the formation of the esters was dependent on the configuration of the boronic acids, apparently influencing the shape and rigidity of the resulting dynamers.

These results show the potential of these systems to enable enhanced stimuli-responsive systems, operating under the influence of either, or both, reaction type. For example, the construction of logic $A N D$-gates can be envisaged, in which the overall assembly would be activated only if the conditions for both reactions were met, i.e. by requiring boronate exchange and the presence of a base. In principle, this effect could also be applied to controlled delivery/release systems. Furthermore, a range of polymeric entities with different topologies can be produced. The system thus enables the grafting to and labeling/functionalization of nitroaldol dynamers, formation of main-chain dynamers involving both reaction types, crosslinking of nitroaldol dynamer chains, establishment of folded geometries, etc. Selective chain cleavage, functionalization by biomimetic hydrogenbonding substituents and extension to stimuli-responsive systems and nanomaterials for biomedical applications are thus under further investigation.

\section{Author Information}

\section{Corresponding Author}

E-mail: olof ramstrom@uml.edu

\section{Acknowledgments}

The study was in part supported by the Swedish Research Council and the European Union's H2020 framework programme (under agreement MSCA-ITN-2014-ETN-642192). YQ thanks the Chinese Scholarship Council for a special scholarship award.

\section{REFERENCES}

[1] Y. Zhang, Y. Qi, S. Ulrich, M. Barboiu, O. Ramström, Mater. Chem. Front. 2020, 4, 489-506.

[2] A. Canal-Martín, R. Pérez-Fernández, ACS Omega 2020, 5, 26307-26315.

[3] A. J. Greenlee, C. I. Wendell, M. M. Cencer, S. D. Laffoon, J. S. Moore, Trends Chem. 2020, 2, 1043-1051.

[4] F. V. Lijsebetten, J. O. Holloway, J. M. Winne, F. E. D. Prez, Chem. Soc. Rev. 2020, 49, $8425-8438$. 
[5] F. L. C. Morgan, L. Moroni, M. B. Baker, Adv. Healthc. Mater. 2020, 9, 1901798.

[6] Y. Zhang, M. Barboiu, O. Ramström, J. Chen, ACS Catal. 2019, 10, 1423-1427.

[7] A. M. Hartman, R. M. Gierse, A. K. H. Hirsch, Eur. J. Org. Chem. 2019, 2019, 3581-3590.

[8] H. A. Houck, E. Blasco, F. E. Du Prez, C. Barner-Kowollik, J. Am. Chem. Soc. 2019, 141, 12329-12337.

[9] A. G. Orrillo, A. M. Escalante, M. Martinez-Amezaga, I. Cabezudo, R. L. E. Furlan, Chem. Eur. J. 2019, 25, 1118-1127.

[10] A. Osypenko, S. Dhers, J.-M. Lehn, J. Am. Chem. Soc. 2019, 141, 12724-12737.

[11] P. Frei, R. Hevey, B. Ernst, Chem. Eur. J. 2018, 25, 60-73.

[12] S. M. Jansze, K. Severin, Acc. Chem. Res. 2018, 51, 2139-2147.

[13] C. Chen, J. Tan, M. C. Hsieh, T. Pan, J. T. Goodwin, A. K. Mehta, M. A. Grover, D. G. Lynn, Nat. Chem. 2017, 9, 799-804.

[14] R. Deng, M. J. Derry, C. J. Mable, Y. Ning, S. P. Armes, J. Am. Chem. Soc. 2017, 139, 7616-7623.

[15] Y. Liu, J.-M. Lehn, A. K. H. Hirsch, Acc. Chem. Res. 2017, 50, 376-386.

[16] C. G. Pappas, R. Shafi, I. R. Sasselli, H. Siccardi, T. Wang, V. Narang, R. Abzalimov, N. Wijerathne, R. V. Ulijn, Nat. Nanotechnol. 2016, 11, 960-967.

[17] F. Schaufelberger, O. Ramström, J. Am. Chem. Soc. 2016, 138, 7836-7839.

[18] Y. Jin, Q. Wang, P. Taynton, W. Zhang, Acc. Chem. Res. 2014, 47, 1575-1586.

[19] E. Edeleva, A. Salditt, J. Stamp, P. Schwintek, J. Boekhoven, D. Braun, Chem. Sci. 2019, $10,5807-5814$.

[20] M. Grzelczak, L. M. Liz-Marzán, R. Klajn, Chem. Soc. Rev. 2019, 48, 1342-1361.

[21] M. Hebel, A. Riegger, M. M. Zegota, G. Kizilsavas, J. Gačanin, M. Pieszka, T.

Lückerath, J. A. S. Coelho, M. Wagner, P. M. P. Gois, D. Y. W. Ng, T. Weil, J. Am. Chem.

Soc. 2019, 141, 14026-14031.

[22] Y. Liu, Y. Jia, Q. Wu, J. S. Moore, J. Am. Chem. Soc. 2019, 141, 17075-17080.

[23] S. K. Mellerup, S. Wang, Chem. Soc. Rev. 2019, 48, 3537-3549.

[24] S. Mavila, B. T. Worrell, H. R. Culver, T. M. Goldman, C. Wang, C.-H. Lim, D. W.

Domaille, S. Pattanayak, M. K. McBride, C. B. Musgrave, C. N. Bowman, J. Am. Chem. Soc. 2018, 140, 13594-13598.

[25] Y. Ren, P. H. Svensson, O. Ramström, Angew. Chem. Int. Ed. 2018, 57, 6256-6260.

[26] T. Kosikova, D. Philp, Chem. Soc. Rev. 2017, 46, 7274-7305.

[27] N. Roy, B. Bruchmann, J.-M. Lehn, Chem. Soc. Rev. 2015, 44, 3786-3807.

[28] M. J. Webber, E. A. Appel, E. W. Meijer, R. Langer, Nat. Mater. 2015, 15, 13.

[29] L. Li, C. Yuan, L. Dai, S. Thayumanavan, Macromolecules 2014, 47, 5869-5876.

[30] J. M. García, G. O. Jones, K. Virwani, B. D. McCloskey, D. J. Boday, G. M. ter Huurne, H. W. Horn, D. J. Coady, A. M. Bintaleb, A. M. S. Alabdulrahman, F. Alsewailem, H. A. A. Almegren, J. L. Hedrick, Science 2014, 344, 732-735.

[31] A. Saghatelian, Y. Yokobayashi, K. Soltani, M. R. Ghadiri, Nature 2001, 409, 797-801.

[32] F. Schaufelberger, O. Ramström, Chem. Eur. J. 2021, In press, 10335-10340.

[33] A. Karalius, Y. Zhang, O. Kravchenko, U. Elofsson, Z. Szabó, M. Yan, O. Ramström, Angew. Chem. Int. Ed. 2020, 59, 3434-3438.

[34] C. Biagini, S. D. P. Fielden, D. A. Leigh, F. Schaufelberger, S. Di Stefano, D. Thomas, Angew. Chem. Int. Ed. 2019, 58, 9876-9880.

[35] A. A. Pogodaev, C. L. Fernández Regueiro, M. Jakštaite, M. J. Hollander, W. T. S. Huck, Angew. Chem. Int. Ed. 2019, 58, 14539-14543.

[36] J. Leira-Iglesias, A. Tassoni, T. Adachi, M. Stich, T. M. Hermans, Nat. Nanotechnology 
2018, 13, 1021-1027.

[37] Y. Ren, S. Xie, E. Svensson Grape, A. K. Inge, O. Ramström, J. Am. Chem. Soc. 2018, 140, 13640-13643.

[38] B. Rieß, J. Boekhoven, ChemNanoMat 2018, 4, 710-719.

[39] P. Xing, H. Chen, L. Bai, A. Hao, Y. Zhao, ACS Nano 2016, 10, 2716-2727.

[40] S. Billiet, K. De Bruycker, F. Driessen, H. Goossens, V. Van Speybroeck, J. M. Winne, F. E. Du Prez, Nat. Chem. 2014, 6, 815-821.

[41] J. Solà, C. Jimeno, I. Alfonso, Chem. Commun. 2020, 56, 13273-13286.

[42] O. Š. Miljanić, Chem 2017, 2, 502-524.

[43] B. A. Grzybowski, K. Fitzner, J. Paczesny, S. Granick, Chem. Soc. Rev. 2017, 46, 5647-5678.

[44] J. M. Lehn, Angew. Chem. Int. Ed. 2013, 52, 2836-50.

[45] N. Zheng, Y. Xu, Q. Zhao, T. Xie, Chem. Rev. 2021, 121, 1716-1745.

[46] S. Huang, X. Kong, Y. Xiong, X. Zhang, H. Chen, W. Jiang, Y. Niu, W. Xu, C. Ren, Eur. Polym. J. 2020, 141, 110094.

[47] M. Podgórski, B. D. Fairbanks, B. E. Kirkpatrick, M. McBride, A. Martinez, A. Dobson, N. J. Bongiardina, C. N. Bowman, Adv. Mater. 2020, 32, 1906876.

[48] A. Gimenez Molina, I. Barvik, S. Müller, J.-J. Vasseur, M. Smietana, Org. Biomol. Chem. 2018, 16, 8824-8830.

[49] R. Merindol, A. Walther, Chem. Soc. Rev. 2017, 46, 5588-5619.

[50] M. Tena-Solsona, J. Boekhoven, Isr. J. Chem. 2019, 59, 898-905.

[51] A. K. H. Hirsch, E. Buhler, J.-M. Lehn, J. Am. Chem. Soc. 2012, 134, 4177-4183.

[52] J. F. Reuther, S. D. Dahlhauser, E. V. Anslyn, Angew. Chem. Int. Ed. 2018, 58, 74-85.

[53] A. Wilson, G. Gasparini, S. Matile, Chem. Soc. Rev. 2014, 43, 1948-62.

[54] A. V. Gromova, J. M. Ciszewski, B. L. Miller, Chem. Commun. 2012, 48, 2131.

[55] Z. Hassan, Y. Matt, S. Begum, M. Tsotsalas, S. Bräse, Adv. Funct. Mater. 2020, 30, 1907625.

[56] X. Wang, P. Gao, Y. Yang, H. Guo, D. Wu, Nat. Commun. 2018, 9, 2772.

[57] S. Cho, S. Y. Hwang, D. X. Oh, J. Park, J. Mater. Chem.A 2021, 9, 14630-14655.

[58] F. Zhao, A. Dong, L. Deng, R. Guo, J. Zhang, Polym. Chem. 2019, 10, 2436-2446.

[59] M. A. Martínez-Aguirre, J. M. del Campo, S. Escalante-Tovar, A. K. Yatsimirsky, RSC $A d v$. 2015, 5, 30075-30083.

[60] Y. Furikado, T. Nagahata, T. Okamoto, T. Sugaya, S. Iwatsuki, M. Inamo, H. D. Takagi, A. Odani, K. Ishihara, Chem. Eur. J. 2014, 20, 13194-202.

[61] S. D. Bull, M. G. Davidson, J. M. H. van den Elsen, J. S. Fossey, A. T. A. Jenkins, Y.-B. Jiang, Y. Kubo, F. Marken, K. Sakurai, J. Zhao, T. D. James, Acc. Chem. Res. 2013, 46, 312-326.

[62] J. F. Teichert, D. Mazunin, J. W. Bode, J. Am. Chem. Soc. 2013, 135, 11314-11321.

[63] H. Höpfl, N. Farfán, J. Organomet. Chem. 1997, 547, 71-77.

[64] P. Vongvilai, O. Ramström, J. Am. Chem. Soc. 2009, 131, 14419-25.

[65] M. Angelin, P. Vongvilai, A. Fischer, O. Ramström, Chem. Commun. 2008, 47, 768-770.

[66] P. Vongvilai, M. Angelin, R. Larsson, O. Ramström, Angew. Chem. Int. Ed. 2007, 46, 948-50.

[67] J. A. Faniran, H. F. Shurvell, Can. J. Chem. 1968, 46, 2089-2095.

[68] J. E. Burch, W. Gerrard, M. Goldstein, E. F. Mooney, H. A. Willis, Spectrochim. Acta 1962, 18, 1403-1419. 